\title{
Promoting positive interactions between midwives and obstetricians at the primary/secondary interface
}

Rachel Cassie ${ }^{A, B} M M, B M, M B C h B, R M-C^{2}$ Christine Griffiths ${ }^{C}$ PhD, PpHtReo, GCTLT(L7), MA, DipSocSci, RM, RGON • George Parker' PhD, MPhil, GDTE, BM, RM

${ }^{\text {A } C o r r e s p o n d i n g ~}$ Author: rachelcassie@ outlook.co.nz

${ }^{\text {B }}$ Lead Maternity Carer, Waikato, Aotearoa New Zealand

${ }^{\mathrm{C}}$ School of Midwifery, Otago Polytechnic, Wellington, Aotearoa New Zealand

\begin{abstract}
Background: Interprofessional communication is a critical component of safe maternity care. The literature reports circumstances in Aotearoa New Zealand and overseas when interprofessional collaboration works well between midwives and obstetricians, as well as descriptions of unsatisfactory communication between the two professions.
\end{abstract}

Aim: To explore and define effective collaboration between midwives and obstetricians at the primary/ secondary interface in maternity care, in order to generate suggestions to foster positive collaboration.

Method: Eight primary care midwives, three obstetricians and two obstetric registrars from a single District Health Board in Aotearoa New Zealand were interviewed about their interactions at the primary/secondary interface and their understanding, and use, of the Referral Guidelines. The theoretical perspective was Appreciative Inquiry. Data were analysed using thematic analysis.

Findings: Results indicate usually positive interprofessional interactions. Dominant emergent themes are the need to negotiate differing philosophies, to clarify blurred boundaries that sometimes lead to lack of clear lines of responsibility, and the importance of three-way conversations. Of the three themes, this article focuses on three-way communication between midwife, obstetrician/registrar and woman. Participants reported that, when effective three-way communication between woman, midwife and obstetrician occurred, philosophical difference could be negotiated, blurred boundaries clarified and understanding of the respective roles of the LMC midwife and the obstetric team promoted. Participants value the Referral Guidelines but report some limitations to their applicability.

Conclusion: Effective three-way communication promotes good maternity care. This study has identified ways to support optimal communication.

Keywords: interprofessional communication or collaboration, maternity care, midwives, obstetricians, primary/secondary interface

\section{INTRODUCTION}

When women transfer from primary to secondary or tertiary maternity care, pregnancy and/or birthing have departed from normal, sometimes acutely. This is an often stressful and risky time for women. Effective interactions between the health professionals involved are vital in maintaining the safety and wellbeing of women and babies. In Aotearoa New Zealand (Aotearoa NZ) most primary maternity care is carried out by community-based midwives, known as LMCs (Lead Maternity Carers), who practise autonomously and refer to obstetricians and allied medical specialists, within secondary or tertiary maternity hospitals. Care is supported by autonomous hospital-based (core) midwives.

\section{Importance of communication in healthcare}

Effective communication between health professionals has been identified as vital to safe healthcare delivery. Kohn et al. (2000) found that medical errors caused 44,000 to 98,000 deaths annually in hospitals in the United States of America (USA), reporting communication failures as a leading factor in many adverse events. Within maternity care, unsatisfactory communication has a similar role in causing adverse events. An international review, focused on handover of care in maternity, reported obstetrics and gynaecology as being overrepresented in adverse events due to poor handover of care (Spranzi, 2014). In Aotearoa NZ the Perinatal and Maternal Mortality Review Committee (2018), reporting on perinatal loss in 2016, stated communication failures were implicated in potentially avoidable perinatal loss.

\section{Guidelines for Consultation with Obstetric and Related Medical Services (Referral Guidelines)}

Clinical guidelines are used in many healthcare areas, including maternity, to standardise care (Behruzi et al., 2017; Healy \& Gillen, 2016; Skinner \& Foureur, 2010). The Referral Guidelines, published by the Ministry of Health (2012), aim 
to clarify primary/secondary interface interactions in Aotearoa NZ, providing a list of conditions warranting consultation with, or transfer of care to, secondary obstetric services. The Referral Guidelines emphasise the importance of primary/secondary interface communication, epitomised by the explicit requirement for a three-way communication between woman, midwife and obstetrician, whenever there is a consultation with secondary services or a transfer of clinical responsibility. Three studies gave insight into Aotearoa NZ LMC midwives' use of the Referral Guidelines (Norris, 2017; Skinner, 2011; Skinner \& Foureur, 2010). LMC midwives regarded the Referral Guidelines as a useful tool (Norris, 2017; Skinner, 2011). Consistent referral by LMC midwives to secondary or tertiary obstetric care was found across all midwife levels of experience, and regardless of prior nursing or direct entry midwifery education, or whether Aotearoa NZ or overseas midwifery education programmes had been undertaken (Skinner \& Foureur, 2010), suggesting that LMC midwives usually followed recommendations laid down in the Referral Guidelines.

\section{Previous research on professional communication between primary care midwives and obstetricians}

Amongst the literature were descriptions of successful collaboration between midwives and obstetricians, both in Aotearoa NZ (Skinner, 2011; Skinner \& Foureur, 2010) and overseas (Beasley et al., 2012; Chang Pecci et al., 2012; Ogburn et al., 2012; Perdion et al., 2013; Romijn et al., 2018; Stevens et al., 2012). Factors promoting effective communication included flat hierarchies and greater midwifery autonomy (Barker et al., 2019; Beasley et al., 2012; Downe et al., 2010; Skinner \& Foureur, 2010), clear role definitions and boundaries (Munro et al., 2013; Norris, 2017), trust and respect (Chang Pecci et al., 2012; Downe et al., 2010; Lane, 2012), regular interprofessional interaction and use of structured communication tools (Marshall et al., 2009; Norris, 2017; Romijn et al., 2018), robust conflict resolution processes (Chang Pecci et al., 2012), shared education, (Meffe et al., 2012; Murray-Davis et al., 2014) and effective communication systems (Psaila et al., 2015; Schmied et al., 2015; Shaw et al., 2013).

Some studies described predominantly unsatisfactory relationships between obstetricians and midwives (Barker et al., 2019; Behruzi et al., 2017; Downe et al., 2010; Lane, 2012; McFarland et al., 2019; Psaila et al., 2015; Ratti et al., 2014; Reiger, 2011; Schmied et al., 2015; Shaw et al., 2013; Watson et al., 2016). Factors leading to unsatisfactory relationships were historical interprofessional animosity and doctors' mistrust of midwifery education (Downe et al., 2010; Ratti et al., 2014; Watson et al., 2016), power imbalance favouring medical discourses (Barker et al., 2019; Lane, 2012; McFarland et al., 2019; Ratti et al., 2014; Reiger \& Lane, 2009; Watson et al., 2016), differing philosophies and poor information systems and transfer processes (Psaila et al., 2015; Schmied et al., 2015; Shaw et al., 2013).

An Aotearoa NZ postal survey of 433 LMC midwives gave insight into LMC midwifery referral practices (Skinner \& Foureur, 2010). Participants reported on data for 4251 women under their care. Consultation with secondary care was required for $35 \%$ of the women, with $43 \%$ of these referrals requiring transfer of care to obstetric services. LMC midwives continued to provide care in $72 \%$ of instances of transfer of care, demonstrating that LMC midwifery care often continued when secondary services became involved. Predominantly satisfactory relationships between LMC midwives and obstetricians were reported, with $72 \%$ of
LMCs reporting feeling supported by obstetricians to continue care after transfer of clinical responsibility.

A related study evaluated the experiences of a cohort of women requiring transfer of care to secondary services in Christchurch, Aotearoa NZ (Grigg et al., 2015). A postal survey of 174 women six weeks post-partum found generally positive experiences, suggesting that communication practices between their midwives and the obstetricians they were referred to, usually led to positive outcomes for women. Grigg et al. reported that when unsatisfactory experiences occurred, poor communication by LMC midwives, obstetricians and other health professionals had been a significant factor.

For meaningful collaboration, both parties needed equal input, and women needed involvement in decisions relating to their care. Midwifery autonomy was described as an important factor promoting successful interprofessional collaboration (Beasley et al., 2012; Downe et al., 2010; Hartz et al., 2012). Aotearoa NZ's midwifery-led maternity system fulfils this criterion (Grigg \& Tracy, 2013). Skinner and Foureur (2010) identified that, while a significant proportion of the literature revealed components of positive collaboration between the two professions, there was minimal literature on how to promote positive collaboration.

The literature found on communication and collaboration between midwives and obstetricians emphasised the importance of good communication at the primary/secondary interface but did not explore in detail how to achieve this. This research sought to address this gap by identifying practices and ideas promoting positive interprofessional communication between midwives and obstetricians and the means to promote these practices. The research question is "How can positive communication between LMC midwives and obstetricians be promoted?"

\section{AIM}

This study explored communication at the professional interface between LMC midwives, who provide most primary maternity care in Aotearoa NZ, and obstetricians who provide predominantly secondary or tertiary care. By exploring and defining effective collaboration between midwives and obstetricians at the primary/secondary interface in maternity care, positive interprofessional interactions can be identified.

\section{METHOD}

Ethical approval for the study was obtained from the Otago Polytechnic Ethics Committee on 11 July 2017. To ensure that relevance and safety of the research for Māori were considered, an application for the research to proceed was requested from, and granted by, Otago Polytechnic's Kaitohutohu Office.

The theoretical approach was Appreciative Inquiry (AI). AI was first proposed as a theoretical perspective in the 1980s and initially applied to business (Cooperrider \& Srivastva, 1987). More recently, AI has been adopted in qualitative healthcare studies (e.g. Smythe et al., 2009). The framework of AI encourages description of currently positive experiences, visualisation of ideal circumstances, and development of proposals to achieve this ideal. Application of AI to research involves a cycle described as the $4 \mathrm{D}$ cycle. The $4 \mathrm{D}$ cycle identifies four components: Discovery, Dream, Design, and Destiny (Trajkovski et al., 2013). In Discovery, study participants are encouraged to identify what currently works well. In the Dream component, participants are invited to imagine how things would look in an ideal world. For Design, participants are invited to give practical advice on how to achieve the dream. Destiny refers to participant involvement leading to positive change and further discovery. 
For example, this study found that being known to each other improved interprofessional communication between LMCs and obstetricians (Discovery). Participants wanted to get to know each other more readily (Dream). One suggestion was for new staff members and LMCs to provide introductory vignettes with a photo of themselves for inclusion in the District Health Board's (DHB's) monthly email newsletter (Design). This action aimed to speed the process of becoming known to each other, thereby improving interprofessional communication (Destiny).

\section{Data collection}

To recruit midwifery participants, permission was obtained to use the New Zealand College of Midwives' regional email database to invite LMC midwife member participation. To recruit obstetric participants, a submission was made to the study DHB's research committee. Approval was gained to use the DHB's email database to invite DHB-employed obstetricians and obstetric registrars to participate. The final participants were eight LMC midwives currently practising in the study region, and three obstetricians and two obstetric registrars currently practising in the public sector in the study region.

A semi-structured interview guide was designed, piloted and refined, using the principles of AI. Therefore, the questions were designed to explore the positive aspects of current interprofessional communication and how these could be developed. For example, all participants were asked "Can you describe a situation where communication with a midwife/obstetrician was optimal?" Signed consent for the recorded interview to occur was sought immediately prior to interviews. Interviews were conducted by the primary author, an LMC midwife access holder in the study DHB. All interviews were face-to-face and at a place of choosing of the participant. Interviews were recorded and recordings transcribed by a research assistant. Anonymised transcripts were emailed to participants with a request to check that the transcript was a true representation of their views. One participant removed a story as it was too identifying; otherwise, all were returned with minimal change. Data collection continued until no new information was emerging from the coding of interview transcripts. Coding of data was carried out by the researcher and reviewed by the thesis supervisors.

\section{FINDINGS}

Data analysis resulted in the identification of three themes: a need to negotiate differing philosophies between LMC midwives and obstetricians, a need to clarify blurring of boundaries and professional responsibilities, and the pivotal role of three-way communications between women, midwives and the obstetric team. In this paper, only three-way communication will be addressed in detail, alongside its interaction with the two other themes.

Three-way communication was a key factor in promoting successful interprofessional collaboration, negotiating philosophical difference and clarifying blurred boundaries. Table 1 contains a summary of findings framed by AI.

\section{Positive relationships improve communication}

A common theme of usually positive interprofessional relationships was widely reported by both participant groups. As one midwife participant reflected, I often ring the WAU reg [Women's Assessment Unit registrar]... and I generally find the information I get back is good and I'm usually happy with that (MW1).

Participants identified trust and respect as promoting positive communication between midwives and obstetricians. Respect and trust were promoted by using respectful language, including both LMC midwives and obstetricians in conversations, and by listening and engaging in three-way communication. For example, MW7 reported feeling respected in an acute situation when she was listened to:

I said, "just had the first twin! And I was supporting the tummy for the second one and everybody moved with speed. And I guess there probably was less talking and [the obstetrician] could see what was in front of them... I said to him, 'this is why she was being induced' and I was talking and no one else was questioning me... and everybody just manoeuvred. (MW7)

\section{Personal relationships and interprofessional communication}

The advantage of knowing each other was expressed strongly by both participant groups, promoting trust in clinicians' practice and better understanding of each other's philosophy:
I think traditionally no matter where in the world you are, often doctors will have a different view to birth than midwives will. And a lot of that is just understanding why the midwives believe a certain thing and why the obstetric team may have a certain viewpoint and trying to work somewhere to come in between... when you know each other, things work better but I don't know what the solution is. You have to get to know each other first for that to happen. (OB5)

OB5's observation suggested that collaboration would improve if new doctors and LMC midwives had more opportunities to get to know each other, perhaps outside of the workplace context.

OB2 discussed practical difficulties in emergencies, when she did not know the LMC:
I often find it very difficult because... I don't know their
[the LMC's] name... one of the key things in an emergency is you say, 'Rachel can I get you to...', because you have to get people's attention. (OB2)

OB2's observation recognised a need for clear name and role identification for all health professionals. OB2 proposed that different coloured scrubs for different roles might improve role identification.

Knowing each other makes it easier for midwives to approach obstetricians:

... when you've been around for a while and you know them, you probably are more able to... knock on their door... the longer you've been in the job, the more solid it is for communication. (MW7)

Participants reported that being known to each other was promoted by shared education, interdisciplinary meetings where all were empowered, and social interaction. Participants reported that the study DHB provided some shared events, including perinatal mortality meetings, some education sessions and sporadic other events. Participants commented positively on interdisciplinary scenario-based training such as Practical Obstetric Multi-Professional Training (PROMPT) study days. OB2 used facilitative language to discuss her personal commitment to promoting shared education:

I'd love to see more... coming together of midwives and doctors... that's in a small way what I've tried to facilitate... with the workshops that we've done... I'd love to have midwives in a learning space, to try and just nurture relationships. (OB2) 
Midwife participants' proposals to promote collegiality included open days at birthing units for doctors, regular social events and introducing new DHB staff members and LMCs in DHB newsletters to improve familiarity with each other.

\section{Referral Guidelines as an aid to communication}

Both participant groups valued the Referral Guidelines, reporting that they played a significant role in reducing blurring of boundaries at the primary/secondary interface, ensuring safety for women and babies, and providing reassurance to women, midwives and obstetricians that appropriate timely referral was the expected norm.

\section{I think the guidelines are really good... I think some women are really concerned... that midwives don't want to refer... by showing them that you look at these... they understand... that we do have guidelines for our practice... (MW4) \\ ... it's there, to ensure that LMCs do their minimum duty, and also that obstetricians don't reject really important things. (OB2)}

However, LMC participants discussed incidents where they found it unclear who should be responsible for care after secondary care consultation, and where communications contained incomplete information which could not be queried:

... I just got a text the other night from WAU... which said that my woman had been there... raised blood pressure. She [the woman] text me later to say... 'you need to check my blood pressure in two days' time'... she's 27 weeks, she's got essential hypertension, she's got a BMI [Body Mass Index] of $53 . .$. Is this my job?... The communication I then had... a text from the new WAU communication... saying that they'd seen her, and her follow up was [in] a week, with a scan and a follow up with the obstetric team... There was no request for repeat blood pressure... I didn't actually know, can I reply to that text and say, 'she says she needs a repeat blood pressure?' (MW2)

Under the Referral Guidelines, consultation with secondary services is recommended for hypertension. For a BMI greater than 40 , transfer of care to secondary services is recommended. There are no recommendations around the gestation at which hypertension manifests. The Referral Guidelines specify that after consultation with no transfer of care, the responsibility remains with the LMC midwife, while transfer of care should

Table 1: Summary of findings framed by Appreciative Inquiry

\begin{tabular}{lll} 
Component & Key findings \\
\hline Discovery: & - & Positive interprofessional relationships exist between obstetricians and LMC midwives despite the acknowledged \\
What is already working & & philosophical difference \\
well? & Being known to each other promotes positive interaction \\
& - $\quad$ Shared education and LMC midwife input into policy and protocols promote positive relationships \\
& - The Referral Guidelines improve the clarity of primary/secondary interface boundaries \\
& Coming intermediary midwives relaying information between LMC midwives and obstetricians improves \\
& commication if intermediaries are empowered to negotiate
\end{tabular}

- $\quad$ Phone communication between LMC midwives and obstetricians allows resolution of philosophical difference and blurred boundaries

- When three-way communication occurs effectively, philosophical difference and blurred boundaries are usually resolved

Dream:

What would be ideal?

- A world where all professionals are known to each other

- Optimal three-way communication between woman, LMC midwife and obstetrician at every primary/secondary interface interaction

- $\quad$ Phone calls from obstetrician to LMC midwife whenever there is potential need for negotiation over care

- Empowerment of core midwife intermediaries to negotiate with LMC midwives over secondary care decisions relating to women's care

- Straightforward processes to resolve communication breakdown

- Optimal use of up-to-date communication modalities

\section{Design:}

Participants' proposals to move towards the ideal

- Interprofessional social events for new midwives and obstetric doctors

- Open days at hospital and primary birth centres

- Large name badges, with clear name and role

- $\quad$ New staff members to introduce themselves in DHB electronic newsletters

- Communication between LMC midwife and obstetrician, by phone wherever possible, to negotiate responsibilities for ongoing components of care and timing of birth interventions

- Use speaker phone technology to allow three-way communication to include the LMC midwife in obstetric clinics

- Institute appropriate information technology (IT) systems to facilitate communication between primary and secondary care

- Set up phone and email contact points and pathways to resolve communication issues

- Institute policy allowing intermediary midwives to negotiate timing of inductions and roles for ongoing management following obstetric consultation

Destiny:

Anticipated outcome after instituting participants' proposals
- Social events, shared education and introductory vignettes facilitate being known to each other, leading to improved communication

- Optimal IT use facilitates appropriate timely communications between LMC midwives and obstetricians, improving three-way communication

- Simple processes to resolve breakdown in communication ensure safety for women and promote better three-way communication

- $\quad$ Facilitating women's access to their electronic records improves three-way communication 
result in transfer of responsibility. In the scenario above there was blurring of the boundaries between the ongoing responsibilities of the LMC midwife and the secondary care team. The Referral Guidelines did not clarify responsibilities for providing the extra care required, insufficient information was communicated, and no three-way negotiation occurred. In contrast, a more satisfactory interaction was described by MW1:

... [baby's] growth had dropped down to the 10th centile... she lived in [semi-rural location]... they saw her at [secondary care clinic] and then made a plan with us after communicating with us... [to] have scans in the community... they got what they wanted with the scans but it was woman focussed because she could just go to [radiology unit in her home town]... it meant more work for us but we were happy to do that because it kept her out of the hospital... we still did the monitoring, they're happy, we're happy... that was a phone call as well. (MW1)

The Referral Guidelines recommend consultation when ultrasound scans suggest the baby is small for gestational age (SGA) with an estimated fetal weight on ultrasound scan less than the 10th centile on a customised growth chart. Satisfactory communication was promoted by a timely phone call where the woman's needs were addressed and the roles of the obstetrician and midwife were negotiated, clarifying the primary/secondary interface boundary. The difference between this scenario and the previous one was that the Referral Guidelines' requirement for three-way communication was followed in the second case. Analysis of these two scenarios identified that when three-way communication occurred after consultation, a more satisfactory outcome for the woman, LMC midwife and obstetrician was negotiated.

\section{Three-way negotiation clarifies boundaries and creates common ground}

Participants reported that, when effective three-way communication between woman, midwife and obstetrician occurred, philosophical difference could be negotiated, blurred boundaries clarified and understanding of the respective roles of the LMC midwife and the obstetric team promoted. This was particularly important when a woman's choices fell outside recommended medical practice. The woman's involvement in discussions supported woman-centred care:
... there was this woman who wanted a [vaginal] breech delivery... She knew she [only] wants a doctor to be in once she's fully dilated ... we knew what she wants... When we said, 'we need CTG monitoring' she declined... she knew what the risks are, and she had said 'I will be responsible for this'... So it made it easy for us, not to keep worrying... we won't be involved but we'll stand beside. (OB3)

Three-way negotiation clarified understanding of the woman's choices and the respective roles of the LMC midwife and the obstetric team. The obstetric participant reported reduced anxiety as a result.

Both midwives and obstetricians reported usually positive face-to-face or phone interactions. In most birthing situations, participants reported good three-way communication because all participants were present:

... when everybody's in the same room then actually that works very well... the vast majority of obstetricians are respectful and communicate reasonably well in that threeway process. (MW2)

Obstetric participants reported that LMC midwives occasionally attended secondary care clinic with women. This LMC attendance facilitated constructive three-way conversations but was time inefficient for LMCs:
Do you know what was good? When midwives used to come to clinic with the patients and spend the whole afternoon waiting to be seen!... I know that's not good use of their time... when the LMC knew potentially that the patient was going to be maybe induced or that there was difficulty that they'd come... as their woman's advocate... but it wasn't like them and us. (OB4)

MW1 reported facilitating three-way conversations by phone, advising women to request the obstetrician phone the LMC during their consultations with potential to use speaker phone technology to facilitate three-way conversations:
I said, 'look, if you feel pressured then get them [the obstetrician] to ring me... you've made a good decision. You've made it [based] on informed consent... if you feel pressured or you feel as though you're having to argue your point then you ring us because that's our job'. (MW1)

Three-way communication facilitated by speaker phone technology was more time efficient than attendance at secondary care clinic for the LMC.

\section{Structured communication tools improve communication}

At the time of this study, participants reported that the study DHB policy recommended use of the communication tool SBARR (Situation, Background, Assessment, Recommendation, Response) to organise communication at handover of care. Several participants discussed use of SBARR to give structure to communications between LMC midwives and obstetricians and reported improved content and clarity of communication: Using that SBARR tool is very good so that information that I share with them is concise, objective, and very clear (MW6).

\section{Use of intermediaries}

A significant study finding was that communication between LMC midwives and obstetricians often passed through an intermediary, usually a core midwife. No literature was found directly pertaining to intermediaries in communication chains in healthcare. Two common intermediary roles were identified:

1. Assistant Charge Midwifery Managers (ACMMs), the shift coordinators of delivery suite: LMCs phoned the ACMM rather than an obstetric doctor when admission to the maternity unit was contemplated.

2. Core midwives: In the WAU, or sometimes in secondary care clinic, core midwives phoned LMC midwives to report on ongoing management plans.

Participants acknowledged both roles were important to ensure appropriate information transfer between obstetrician and LMC. Both LMC and obstetric participants reported they were usually satisfied with ACMMs acting as intermediaries. LMC participants saw this arrangement as an improvement on past practice when an obstetric registrar was the first point of call but was often unavailable: 
I do really like the fact that now... we have that one contact with the delivery suite coordinator... for many years it was very difficult to talk to a registrar... it used to be that... you'd spend a lot of time trying to find people. (MW4)

There was less satisfaction with communications relayed from obstetricians in WAU or secondary care clinic to LMCs. Participants reported that, in WAU, no written communication was sent to LMC midwives after consultation. Instead, core midwives usually phoned or texted to inform LMC midwives of outcomes of obstetric consultation, providing information such as timing of induction of labour, secondary care follow-up plan or to request follow-up by the LMC. LMCs reported receiving incomplete information, and dissatisfaction that they were not involved in decisions:

The three-way process when a decision's been made about how to birth the woman is poor... the LMC's usually left out of that three-way conversation. She's usually informed of the outcome of the two-way conversation... [by] someone who wasn't even involved in the two-way conversation! (MW4)

Some obstetric participants were also aware of barriers to successfully achieving a three-way process:

\section{The three-way process is not always optimally facilitated, especially if a woman comes to clinic without a midwife and the clinic is overbooked and you give your recommendation and then the clinic [core] midwives are having that conversation with the [LMC] midwife. (OB1)}

Lack of adequate three-way communication could lead to breakdowns in communication. MW6 noted that addressing breakdowns in communication was not straightforward:

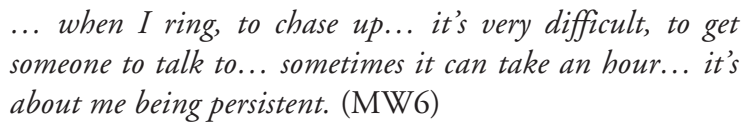

Communication could improve if there were designated pathways for LMCs to address breakdowns in communication and resolve conflict.

MW6 reported a scenario when communication from a core midwife intermediary worked well:

\section{I've had one three-way conversation this year. I had the antenatal [core] midwife ring me to ask did I agree with the date that a woman was going to be booked for an induction. And that would be one of the first times I've ever had a three-way and that was when she was there with the woman as well. (MW6)}

Because she was able to negotiate with the core midwife, the LMC perceived this to be a three-way conversation despite absence of the doctor who had recommended induction of labour.

\section{Technological solutions to improving communication}

Written communication was usually effective if it was timely. However, both participant groups reported that referral letters to secondary care clinics were sent by fax and replies were sent by post. These dated communication modalities impeded communication, as faxed letters commonly went astray, and post could mean delays of up to several weeks.

Increasing numbers of LMCs had remotely accessible electronic record-keeping systems, but these could not interface with the current DHB system, which needed an upgrade for shared electronic records to be contemplated. Two new
DHB initiatives were discussed by midwife participants: text communication by core midwives to communicate decisions for women seen by the obstetric team acutely in WAU; and proposed provision of tablets to all LMC midwives allowing secure access to some DHB records. Introduction of computer tablets for LMCs was regarded positively by LMCs: we're still using fax machines which is so archaic... with the new tablets coming, I still haven't got mine but... I'm really excited about being able to just get lab results (MW8). Tablets would address security for the DHB computer network, improve LMC access to letters, scans and laboratory results, and raise the possibility of more extensive record sharing. Participants advocated for use of secure email to improve speed and reliability of interprofessional communication.

\section{DISCUSSION}

Participants from both professional groups reported usually positive interprofessional relationships. This finding echoed that of Skinner and Foureur (2010), who found usually positive relationships between LMCs and obstetricians nationwide, suggesting that similarly positive relationships might be found in other New Zealand DHBs. Positive relationships set the stage for good interprofessional communication and were promoted when obstetricians and LMC midwives were known to each other. Participants identified proposals to improve familiarity with each other and these could be readily implemented with minimal cost. For example, vignettes and photos of new LMCs, obstetricians and other staff could be provided by new practitioners and included in already established electronic newsletters.

Other ways participants identified of getting to know each other were shared interprofessional education and meetings (such as at the perinatal mortality meetings and the collaborative production of guidelines and protocols). This reflects the findings of other studies which identified that sharing of education and policy decision making contributed to positive interprofessional relationships (Chang Pecci et al., 2012; Meffe et al., 2012; Murray-Davis et al., 2014; Ratti et al., 2014). One participant recognised that sharing more existing education with members of both professions and the development of new shared educational opportunities would support further collegiality.

Communication could be further improved in acute situations by the provision of large badges identifying the name and role of the practitioners, and the promotion and use of the communication tool SBARR.

Effective three-way communication was critical in clarifying responsibilities of core and LMC midwives and obstetricians at transfer of care to resolve blurring of boundaries and maintain safety for mothers and babies. When three-way communication occurred effectively, study findings indicated usually satisfactory outcomes for midwives and obstetricians, and promotion of woman-centred care. This identified a need to promote threeway communication.

Chang Pecci et al. (2012) argue that systems and processes to resolve communication conflict are equally important. The current research identifies that at times there were difficulties with communication. One way to resolve this issue was having phone conversations to debate decisions relating to care and negotiate the ongoing care plan. The identification of the core midwife as an intermediary is an important finding of this study. These midwives were able to provide a pathway of communication between obstetricians and LMC midwives and have an important role in improving information transfer. 
Such intermediaries are most effective if they are empowered to negotiate with the LMC midwife on key management decisions, facilitating an indirect three-way process. The establishment of clear feedback pathways for LMC midwives is recommended to support improved clarity and manage instances where women are unhappy with outcomes of obstetric consultations, or when referrals are lost.

Another way to improve communication is the ability to share information through the use of IT, including email communication and shared electronic records, to facilitate timely sharing of written information. Maternity hospitals should review their IT systems to maximise safe interprofessional communication.

\section{STRENGTHS AND LIMITATIONS}

The focus of this study was the relationship between obstetricians and midwives. A study strength is the ability to contrast and compare the views of two participant groups holding differing philosophical standpoints, seeking means to promote positive interprofessional communication between these two groups. The study does not examine women's perspectives of the primary/secondary interface interactions between midwives and obstetricians, although the critical importance of always maintaining the woman's involvement in decisions about her own care is underlined. Further study examining women's perspectives would complete a triangle of understanding of three-way communication, elucidate to what extent the two professions are providing a service satisfactory to women and explore what women's visons for improvement might be.

The research occurred within one maternity hospital in one region. DHBs vary in size, staffing levels, culture, policies and procedures and therefore care must be taken not to generalise our findings. The research findings align sufficiently with those found in other studies to suggest that there are common components to supporting optimal relationships and good communication which may have relevance to other Aotearoa NZ maternity hospitals and overseas maternity care providers.

\section{CONCLUSION}

The point where pregnancy and birthing diverge from normal is a vulnerable time for women and babies. Effective communication between LMC midwives and obstetricians at the primary/secondary interface has previously been identified as vital to maintaining safe, satisfactory maternity experiences. This research sought understanding of what is working well in situations requiring collaboration between LMCs and obstetricians, and to propose actions to promote optimal communication. The emergent themes are the need to negotiate philosophical difference, to clarify blurred boundaries, and the vital role of three-way communication between women, LMC midwives and obstetricians in the facilitation of collaboration between the two professions.

Study findings indicate that the ideal of positive interprofessional relationships between LMCs and obstetricians can coexist despite philosophical difference. Effective three-way communication usually resolves philosophical difference and blurred boundaries, facilitating provision of safe, woman-centred care.

Participants have useful suggestions to improve communication between midwives and obstetricians and to overcome barriers to effective three-way communication. A framework of AI is applied using participants' ideas to generate proposals to promote collaboration between the two professions, many of which could be implemented at low cost. To optimise the safety of mothers and babies and facilitate positive collaboration between LMC midwives and obstetric doctors, three-way communication, as identified in the Guidelines (Ministry of Health, 2012), needs to become a universal part of maternal healthcare, in reality, every time there is consultation, transfer of care or shared care.

\section{CONFLICT OF INTEREST DISCLOSURE}

The authors declare that there are no conflicts of interest.

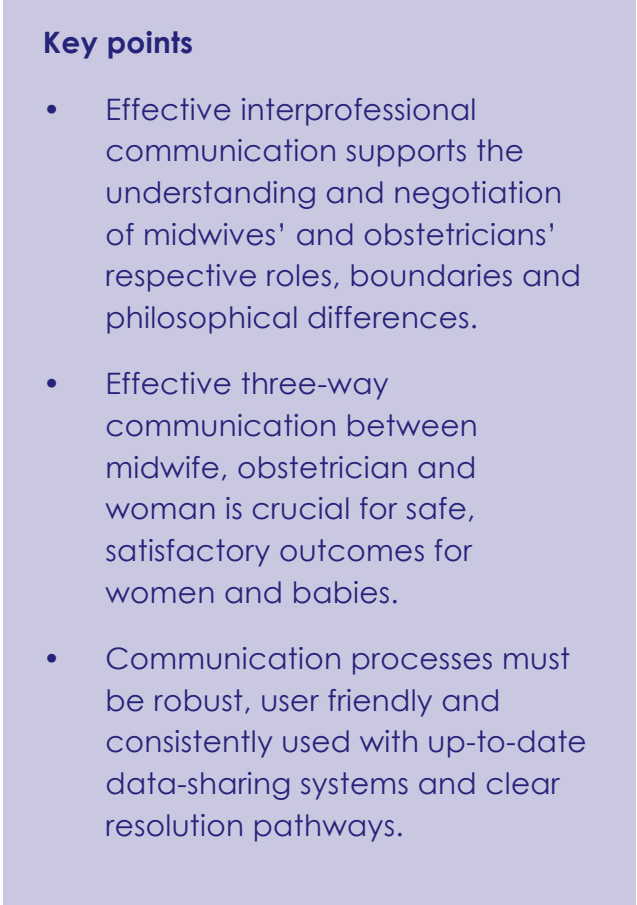

\section{REFERENCES}

Barker, M., Fenwick, J., \& Gamble, J. (2019). Midwives' experiences of transitioning into private practice with visiting access in Australia: A qualitative descriptive study. International Journal of Childbirth, 9(3), 145-157. https://doi.org/10.1891/IJCBIRTH-D-19-00031

Beasley, S., Ford, N., Tracy, S. K., \& Welsh, A. W. (2012). Collaboration in maternity care is achievable and practical. Australian \& New Zealand Journal of Obstetrics \& Gynaecology, 52(6), 576-581. https://doi.org/10.1111/ajo.12003

Behruzi, R., Klam, S., Dehertog, M., Jimenez, V., \& Hatem, M. (2017). Understanding factors affecting collaboration between midwives and other health care professionals in a birth center and its affiliated Quebec hospital: A case study. BMC Pregnancy and Childbirth, 17(1), 200. https://doi.org/10.1186/s12884-017-1381-x

Chang Pecci, C., Mottl-Santiago, J., Culpepper, L., Heffner, L., McMahan, T., \& Lee-Parritz, A. (2012). The birth of a collaborative model: Obstetricians, midwives, and family physicians. Obstetrics \& Gynecology Clinics of North America, 39(3), 323-334. https:// doi. org/10.1016/j.ogc.2012.05.001

Cooperrider, D., \& Srivastva, S. (1987). Appreciative inquiry in organizational life. Research in Organizational Change and Development, 1,129-169.

Downe, S., Finlayson, K., \& Fleming, A. (2010). Creating a collaborative culture in maternity care. Journal of Midwifery \& Women's Health, 55(3), 250-254. https://doi.org/10.1016/j.jmwh.2010.01.004 Grigg, C. P., \& Tracy, S. K. (2013). New Zealand's unique maternity system. Women and Birth, 26(1), e59-e64. https://doi.org/10.1016/j. wombi.2012.09.006

Grigg, C. P., Tracy, S. K., Schmied, V., Monk, A., \& Tracy, M. (2015). Women's experiences of transfer from primary maternity unit to tertiary hospital in New Zealand: Part of the prospective cohort Evaluating Maternity Units study. BMC Pregnancy and Childbirth, 15, 339. https:// doi.org/10.1186/s12884-015-0770-2

Hartz, D. L., Foureur, M., \& Tracy, S. K. (2012). Australian caseload midwifery: The exception or the rule. Women and Birth. 25(1), 39-46. https://doi.org/10.1016/j.wombi.2011.01.001 
Healy, M., \& Gillen, P. (2016). Planning birth in and admission to a midwife-led unit: Development of a GAIN evidence-based guideline. MIDIRS Midwifery Digest, 27(1), 26-32.

Kohn, L., Corrigan, J., \& Donaldson, M. (2000). To err is human: Building a safer health system. National Academies Press.

Lane, K. (2012). When is collaboration not collaboration? When it's militarized. Women and Birth, 25(1), 29-38. https://doi.org/10.1016/j. wombi.2011.03.003

Marshall, S., Harrison, J., \& Flanagan, B. (2009). The teaching of a structured tool improves the clarity and content of interprofessional clinical communication. Quality \& Safety in Health Care, 18(2), 137140. https://doi.org/10.1136/qshc.2007.025247

McFarland, A., Jones, J., Luchsinger, J., Kissler, K., \& Smith, D. (2019). The experiences of midwives in integrated maternity care: A qualitative metasynthesis. Midwifery, 80, 102544. https://doi. org.10.1016/j.midw.2019.102544

Meffe, F., Moravac, C. C., \& Espin, S. (2012). An interprofessional education pilot program in maternity care: Findings from an exploratory case study of undergraduate students. Journal of Interprofessional Care, 26(3), 183-188. https://doi.org/10.3109/13561 820.2011 .645089

Ministry of Health. (2012). Guidelines for Consultation with Obstetric and Related Medical Services (Referral Guidelines). https://www.health. govt.nz/publication/guidelines-consultation-obstetric-and-relatedmedical-services-referral-guidelines

Munro, S., Kornelsen, J., \& Grzybowski, S. (2013). Models of maternity care in rural environments: Barriers and attributes of interprofessional collaboration with midwives. Midwifery, 29(6), 646652. https://doi.org/10.1016/j.midw.2012.06.004

Murray-Davis, B., McDonald, H., Rietsma, A., Coubrough, M., \& Hutton, E. (2014). Deciding on home or hospital birth: Results of the Ontario Choice of Birthplace Survey. Midwifery, 30(7), 869-876. https://doi.org/10.1016/j.midw.2014.01.008

Norris, M. (2017). What works well at the interface of midwifery care handover. A qualitative study [Master's thesis, Auckland University of Technology]. Tuwhera. https://openrepository.aut.ac.nz/ handle/10292/11011

Ogburn, J., Espey, E., Pierce-Bulger, M., Waxman, A., Allee, L., Haffner, W., \& Howe, J. (2012). Midwives and obstetriciangynecologists collaborating for Native American women's health. Obstetrics \& Gynecology Clinics of North America, 39(3), 359-366. https://doi.org/10.1016/j.ogc.2012.05.004

Perdion, K., Lesser, R., Hirsch, J., Barger, M., Kelly, T., Moore, T., \& Lacoursiere, D. (2013). A midwifery-led in-hospital birth center within an academic medical center: Successes and challenges. Journal of Perinatal \& Neonatal Nursing, 27(4), 302-310. https://doi.org/101097/ JPN.0b013e3182a3cd42

Perinatal and Maternal Mortality Review Committee. (2018). Twelfth annual report of the Perinatal and Maternal Mortality Review Committee. https://www.hqsc.govt.nz/assets/PMMRC/Publications/12thPMMRC-report-final.pdf

Psaila, K., Schmied V., Fowler C., \& Kruske, S. (2015). Interprofessional collaboration at transition of care: Perspectives of child and family health nurses and midwives. Journal of Clinical Nursing, 24(1-2), 160-172. https://doi.org/10.1111/jocn.12635

Ratti, J., Ross, S., Stephanson, K., \& Williamson, T. (2014). Playing nice: Improving the professional climate between physicians and midwives in the Calgary area. Journal of Obstetrics \& Gynaecology Canada, 36(7), 590-597. https://doi.org/10.1016/S17012163(15)30538-7

Reiger, K. (2011). “Knights” or "knaves"? Public policy, professional power, and reforming maternity services. Health Care for Women International, 32(1), 2-22. https://doi.org/10.1080/07399332.2010.5 29218

Reiger, K., \& Lane, K. (2009). Working together: Collaboration between midwives and doctors in public hospitals. Australian Health Review, 33(2), 315-324. https://doi.org/10.1071/ah090315

Romijn, A., Teunissen, P., de Bruijne, M., Wagner, C., \& de Groot, C. (2018). Interprofessional collaboration among care professionals in obstetrical care: Are perceptions aligned? British Medical Journal: Quality \& Safety, 27, 279-286. https://doi.org/10.1136/ bmjqs-2016-006401
Schmied, V., Homer, C., Fowler, C., Psaila, K., Barclay, L., Wilson, I., Kemp, L., Fasher, M., \& Kruske, S. (2015). Implementing a national approach to universal child and family health services in Australia: Professionals' views of the challenges and opportunities. Health \& Social Care in the Community, 23(2), 159-170. https://doi.org/10.1111/ hsc. 12129

Shaw, B., Hamilton, S., \& McCullough, M. (2013). Collaborative working within community maternity services - Is this the chink in the armour? British Journal of Midwifery, 21(4), 285-291. https://doi. org/10.12968/bjom.2013.21.4.285

Skinner, J. (2011). Being with women with risk: The referral and consultation practices and attitudes of New Zealand midwives. New Zealand College of Midwives Journal, 45, 17-20.

Skinner, J., \& Foureur, M. (2010). Consultation, referral, and collaboration between midwives and obstetricians: Lessons from New Zealand. Journal of Midwifery and Women's Health, 55(1), 28-37. https:// doi.org/10.1016/j.jmwh.2009.03.015

Smythe, L., Payne D., Wilson S., \& Wynyard, S. (2009). Warkworth Birthing Centre: Exemplifying the future. New Zealand College of Midwives Journal, 41, 7-11.

Spranzi, F. (2014). Clinical handover on the labour ward: A narrative synthesis of the literature. British Journal of Midwifery, 22(10), 738-745. https://doi.org/10.12968/bjom.2014.22.10.738

Stevens, J., Witmer, T., Grant, R., \& Cammarano, D. (2012). Description of a successful collaborative birth center practice among midwives and an obstetrician. Obstetrics \& Gynecology Clinics of North America, 39(3), 347-357. https://doi.org/10.1016/j.ogc.2012.05.003

Trajkovski, S., Schmied, V., Vickers, M., \& Jackson, D. (2013). Using appreciative inquiry to transform health care. Contemporary Nurse, 45(1), 95-100. https://doi.org/10.5172/conu.2013.45.1.95

Watson, B. M., Heatley, M. L., Gallois, C., \& Kruske, S. (2016). The importance of effective communication in interprofessional practice: Perspectives of maternity clinicians. Health communication, 31(4), 400-407.

\section{Accepted for Publication July 2021}

Cassie, R., Griffiths, C., \& Parker, G. (2021). Promoting positive interactions between midwives and obstetricians at the primary/ secondary interface. New Zealand College of Midwives Journal, 57, 41-48. https://doi.org/10.12784/nzcomjnl57.2021.6.41-48 